\title{
A DINÂMICA DAS ÁREAS DE CONSERVAÇÃO DO BRASIL E MOÇAMBIQUE: ESTUDO COMPARATIVO DA SERRA DO JAPI, MATA SANTA GENEBRA E A RESERVA NACIONAL DO NIASSA
}

\author{
NHACHUNGUE, Francisco Gonçalves"; SEIXAS, Sônia Regina da Cal²; BANDEIRA, \\ Benjamim Olinda ${ }^{3}$.
}

\section{RESUMO}

O objetivo deste artigo é compreender as dinâmicas de conservação da biodiversidade do Brasil e de Moçambique. Especificamente pretende i) caracterizar as três áreas de conservação e a legislação inerente à conservação da biodiversidade em ambos os países; ii) comparar os modelos de gestão das três áreas; iii) identificar as diferenças e similaridades nessas áreas de conservação. Com uma abordagem qualitativa, a pesquisa baseou-se na revisão bibliográfica e documental e consubstanciada pelas técnicas de observação direta e diálogo, bem como o registo de imagens fotográficas. Os resultados mostraram a semelhança dos modelos de gestão nessas três áreas, e todas são habitadas, no seu interior e entorno, por população de diferentes classes sociais. Porém, há diferença de contextos em ambos os países. Enquanto a gestão das Unidades de Conservação brasileiras desafia o crescimento urbano, industrialização, privatização de terras, a gestão da Reserva Nacional do Niassa desafia as atividades de extrativismo ambiental (caça ilegal, queimadas descontroladas, mineração ilegal) para autossubsistência, com recurso a meios e técnicas tradicionais e perniciosas ao meio e à integridade dos recursos em conservação.

Palavras-chave: Conservação. Unidades/Áreas. Modelos. Gestão.

\begin{abstract}
The purpose of this paper is to understand the biodiversity conservation dynamics of Brazil and Mozambique. Specifically it intends to i) characterize three conservation areas and the inherent legislation of biodiversity conservation in both countries; ii) compare management models of the three areas; iii) identify the differences and similarities in these conservation areas. With a qualitative approach, the research was based on bibliographic and documentary review and substantiated by the techniques of direct observation and dialogue, as well as the recording of photographic images. The results showed the similarity of management models in these three areas and all of them are inhabited inside and around, by population of different social classes. However, there is a difference in contexts in both countries. While the management of Brazilian protected areas challenges urban growth, industrialization, land privatization; Niassa National Reserve management challenges environmental extraction activities (poaching, uncontrolled burning, illegal mining) to self-subsistence, using traditional and environmentally harmful means and techniques to maintain the integrity of conservation resources.
\end{abstract}

Keywords: Conservation. Units/Areas. Models. Management.

\footnotetext{
${ }^{1}$ Docente na UNIROVUMA - Extensão de Niassa (Moçambique) e doutorando em Energia e Meio Ambiente na Universidade Pedagógica de Maputo.

2 Doutora em Ciências Sociais IFCCH/ UNICAMP. Professora no NEPAM e PSE/UNICAMP (Brasil) e Coorientadora da tese.

${ }^{3}$ Professor Doutor no Departamento de Biologia/UP Maputo (Moçambique) e Orientador da tese.
} 


\section{Introdução}

Atualmente denota-se uma tendência de agravamento dos problemas ambientais, com especial atenção aos associados aos processos de desmatamento ${ }^{4}$, por um lado, por práticas agropastoris, caça e outras práticas de subsistência desencadeadas por populações vulneráveis, por outro, para fins de especulação imobiliária e agrícola, urbanização, industrialização, entre outros. Os limites das áreas de conservação têm sido reduzidos (downsizing) devido a essas práticas (CHARDONNET, 2019). As discussões sobre a conservação da biodiversidade têm estimulado interesses de diversas entidades sociais, políticas e econômicas, com especial atenção para a necessidade de envolvimento ativo das comunidades locais nos processos de gestão dessas áreas.

Este artigo procura partilhar algumas realidades de experiências de gestão de áreas de conservação da biodiversidade do Brasil e de Moçambique. Na sequência do estágio de doutorado em 2018 na Universidade Estadual de Campinas, no Brasil, foram visitadas duas Unidades de Conservação da biodiversidade: a Serra do Japi (SJ), ou Reserva Biológica da Serra do Japi (RBSJ), e a Mata Santa Genebra (MSG), ambas remanescentes da Mata Atlântica do estado de São Paulo, localizadas nos municípios de Jundiaí e Campinas, respectivamente. Como forma de compreender a dinâmica e sistemas de gestão dessas unidades, levantam-se aqui algumas discussões comparando as áreas brasileiras e uma das áreas de conservação do norte de Moçambique: a Reserva Nacional do Niassa (RNN). Esta última é objeto de tese em andamento $^{5}$ e é uma das maiores reservas de fauna bravia da África Austral cujos modelos de gestão estão em transformação, desde o ano de 1995, quando deram início aos trabalhos de recuperação e restauração pós-conflito armado que durou 16 anos no País, tendo passado pela gestão da "Sociedade de Gestão da Reserva do Niassa" e atualmente pela parceria públicoprivada (Governo através da $\mathrm{ANAC}^{6}+\mathrm{WCS}^{7}$ ) e comunidades locais. Atualmente decorre o processo de concepção de novo Plano de Manejo que, inclusive, propõe a recategorização da RNN, passando a designar-se Reserva Especial (RE), com vista a adequar-se ao novo modelo de gestão.

\footnotetext{
${ }^{4} \mathrm{O}$ desmatamento assume também a forma de incêndios florestais, como os que devastaram vastas extensões florestais em Pedrógão Grande (Portugal) na segunda quinzena de junho de 2017 e atualmente na Amazônia, durante a segunda quinzena de agosto de 2019.

${ }^{5}$ Avaliação de percepções ambientais sobre o modelo de gestão da RNN. Estudos de casos das localidades de Lugenda e Mecula-Sede.

${ }^{6}$ Administração Nacional das Áreas de Conservação.

${ }^{7}$ Wild Conservation Society.
} 
As duas Unidades de Conservação brasileiras atrás mencionadas são Áreas de Proteção Ambiental (APAs) da Mata Atlântica, cujo processo de sua preservação desafia os progressos de urbanização, industrialização e privatização de terras (HOEFFEL; FADINI; SEIXAS, 2010).

\section{Objetivo}

O objetivo geral deste estudo é compreender as dinâmicas de conservação da biodiversidade do Brasil e de Moçambique. Os objetivos específicos são: i) caracterizar as três áreas de conservação e a legislação inerente à conservação da biodiversidade no Brasil e em Moçambique; ii) comparar os modelos de gestão das três áreas; iii) identificar as diferenças e similaridades nessas áreas de conservação. A pesquisa é qualitativa e baseou-se na revisão bibliográfica e documental de diversos estudos realizados por diversas entidades acadêmicas como o NEPAM/UNICAMP; Instituto de Biologia/UNICAMP; IFCH/UNICAMP e outros. Foram igualmente utilizadas as técnicas de observação direta e diálogo com os diferentes interlocutores nas três áreas do estudo, bem como o registo de imagens fotográficas.

Além da introdução, o artigo discute na sua estrutura algumas abordagens sobre a conservação da biodiversidade, especialmente para as três áreas de conservação nos dois países em estudo, seguidamente trata da metodologia e por fim tem as considerações finais e as referências bibliográficas.

\section{Referencial teórico}

Uma paisagem é formada pelos fatos antigos e recentes. Neste contexto procuremos compreender a organização do espaço e sua evolução mediante o processo dialético entre formas, estruturas, processos e funções pelo tempo, na perspectiva de Santos (2002). A Forma é o aspecto visível de uma coisa, isto é, o arranjo ordenado de objetos obedecendo a um padrão em determinado período (tempo). Função é a utilidade, aplicação ou tarefa, quer de uma pessoa, instituição ou objeto. A Estrutura corresponde à inter-relação de todas as partes de um todo, o modo de organização ou construção, e Processo é uma ação contínua desenvolvendo-se em direção a um resultado qualquer, implicando tempo, continuidade e mudança (SANTOS, 2008). Nessa sequência, as formas são governadas pelo presente, muitas vezes ignorando seu passado, o que não é ideal, pois as formas surgiram dotadas de certas funções no passado, pelo que o passado não pode ser dissociado das formas de hoje. As formas ou artefatos de uma paisagem são o resultado de processos do passado, ocorridos na estrutura subjacente, e as suas diferenças resultam de situações extremamente diversas, transformando as formas naturais em estruturas 
sociais ou artificiais. Portanto, a compreensão da organização espacial faz-se mediante a combinação das categorias forma, função, estrutura e processo e numa perspectiva holística para apurar a totalidade espacial. De acordo com Santos (2008, p. 71):

[...] forma, função, processo e estrutura devem ser estudados concomitantemente e vistos na maneira como interagem para criar e moldar o espaço através do tempo. A descrição não pode neglicenciar nenhum dos componentes de uma situação. Só se pode compreender plenamente cada um deles na medida em que funciona no interior da estrutura total, e esta, na qualidade de uma complexa rede de interações, é maior que a mera composição das partes [...] em sua configuração tais componentes nem são estáticos nem limitados em seu crescimento.

Assim, torna-se prático ao observador/pesquisador entender a forma com que determinadas paisagens se apresentam, o que poderá implicar a sua função; a estrutura será o que resulta da combinação das formas e funções, e o processo está diretamente ligado ao elemento tempo (contexto). Assim, a dinâmica (processo) das paisagens está ligada às formas (configuração) do passado que conferiram determinadas funções (aplicações) aos seus elementos, numa determinada estrutura (conjuntura).

Numa análise similar ao silogismo, pode-se tirar as seguintes ilações: historicamente, as paisagens (configurações ou formas) naturais da Mata Atlântica, especialmente da Mata Santa Genebra e Serra do Japi, passaram por processos de transformação decorridos por processos de produção agrícola, industrialização e consumo, tendo resultado nas mudanças da cobertura vegetal do solo devido à utilização de técnicas cada vez mais modernas associadas à construção de infraestruturas rodoviárias, residenciais e de comercialização dos produtos industrializados. Nesse processo, a forma inicial da paisagem, tendo sofrido intervenção técnica do ser humano, mudou de sua função, que era prover os serviços ecossistêmicos grátis e básicos para a sobrevivência humana, passando a apresentar novas formas artificiais associadas às conjunturas socioeconômicas, políticas e culturais em cada momento histórico. Santos (2008), suportandose pela teoria dos lugares centrais, prossegue afirmando que a forma só se torna relevante quando a sociedade lhe confere um valor social, e tal valor relaciona-se com a estrutura social inerente ao período. Daí que o acompanhamento das transformações tanto dos elementos naturais em recursos sociais quanto a mudança que esses novos recursos sofrem com o decorrer do tempo se torna imprescindível, é necessário analisar inteiramente a estrutura social em cada período histórico.

O mesmo autor afirma, ainda, que as mudanças espaciais têm caráter econômico, cultural e político-ideológico, que intrinsecamente se une às instâncias de produção, circulação, 
distribuição e consumo que configuram as estruturas das sociedades. Os processos de ordem econômica, institucional, político-ideológica incidentes em determinadas áreas interferem na organização espacial local ou regional, precarizando as condições de vida locais e proporcionando mudanças rápidas e profundas. São exemplos disso a organização de redes de transportes e respectivas vias, de modo a corresponder à demanda da estrutura profissional nova.

As mudanças paisagísticas locais ou regionais decorrem de processos de inovações técnicas, ou seja, a utilização de novas técnicas. Para Santos (2008) as alterações locais e regionais das paisagens decorrem de imposições de nível macro ao micro, tanto em diferentes velocidades quanto em diferentes direções, o que leva ao surgimento de determinadas configurações mais bem preparadas para certas inovações do que outras. Em termos específicos, tem-se áreas em que: i) as inovações podem ser imediatamente aceitas e integradas ao sistema; ii) as inovações precisam passar por um maior número de distorções a fim de se integrarem ao sistema e iii) a estrutura imposta mantém uma imposição tão grande relativamente às formas existentes que estas nunca se acham inteiramente integradas ao novo; este e o velho operam lado a lado, embora não sejam duas entidades separadas e autônomas.

A paisagem esverdeada, natural e com valores estéticos, medicinais e outros atrativos para fins de lazer e o desfrute de serviços ambientais considerados gratuitos oferecidos pela natureza foram substituídos pela paisagem intervencionada pelo ser humano.

Cabe ressaltar, de acordo com Ballerini e Galhardi (2014), que os ecossistemas prestam serviços diversificados à humanidade, com destaque para: i) Serviços de provisão ou de abastecimento: alimentos, água, madeira para combustível, fibras, bioquímicos e recursos genéticos; ii) Serviços de regulação: regulação climática, de doenças, de danos naturais, biológica, polinização e purificação da água; iii) Serviços culturais: ecoturismo e recreação, espiritual e religioso, estético e de inspiração, educacional, senso de localização, herança cultural; iv) Serviços de suporte: formação do solo, produção de oxigênio, ciclo de nutrientes e produção primária.

Dada a relevância socioecológica e ambiental dos diferentes Serviços prestados pelos ecossistemas à humanidade, apresenta-se a seguir e, em linhas gerais, a contextualização das Unidades de Conservação da Biodiversidade da Mata Atlântica Brasileira e de Moçambique, analisadas neste artigo. 


\subsection{A Mata Atlântica brasileira}

A exploração dos recursos florestais brasileiros para alimentar as indústrias manufatureiras europeias (Itália, França e outras) data desde o séc. XVI, época em que Pedro Álvares Cabral atracou no sul da Bahia (LIMA; CAPOBIANCO, 1997). Conforme os mesmos autores, a descoberta do "pau-brasil" na região costeira brasileira incentivou a sua exploração e constituiu o gatilho para a exploração dos recursos florísticos que resultou no desmatamento de extensas áreas da Mata Atlântica. A expansão das commodities açucareiras e de cafezais demandava muita energia da biomassa lenhosa, por um lado, e, por outro, a atividade pecuária, assentamentos coloniais e processos de urbanização devastaram extensas áreas de florestas que se repercutiram até a atualidade (LIMA; CAPOBIANCO, 1997; SERRÃO, 2002).

"O território original da Mata Atlântica ocupava toda a zona costeira brasileira, do Rio Grande do Norte ao Rio Grande do Sul, e se estendia por centenas de quilômetros, continente adentro, nas regiões Sul e Sudeste, chegando a Argentina e Paraguai [...]" (LIMA; CAPOBIANCO, 1997).

O reconhecimento da importância ambiental e social da Mata Atlântica como Patrimônio Nacional brasileiro foi através da Constituição Federal de 5 de outubro de 1988, segundo a qual: “A Floresta Amazônica brasileira, a Mata Atlântica (...) são patrimônio nacional e sua utilização far-se-á, na forma da lei, dentro de condições que assegurem a preservação do meio ambiente, inclusive quanto ao uso dos recursos naturais" (SENADO FEDERAL, 2016, p. 131).

Cronologicamente, as lutas pela defesa da Mata Atlântica tiveram seu início na segunda metade do séc. XX. O quadro 1 abaixo mostra alguns dados cronológicos de defesa desse Patrimônio Nacional brasileiro.

Quadro 1: Dados cronológicos de defesa do Patrimônio Nacional brasileiro

(continua)

\begin{tabular}{|l|l|}
\hline Ano & Ações de defesa da biodiversidade \\
\hline 1987 & $\begin{array}{l}\text { Lançamento da Campanha “Estão tirando o verde de nossa Terra”, impulsionada pela imprensa } \\
\text { nacional e mídias eletrônicas. }\end{array}$ \\
\hline 1988 & A Mata Atlântica é declarada Patrimônio Nacional pela Constituição Federal de 1988. \\
\hline 1990 & $\begin{array}{l}\text { Conclusão do mapeamento dos remanescentes da Mata Atlântica, através de imagens-satélites na } \\
\text { escala 1: 1000.000. }\end{array}$ \\
\hline 1991 & A UNESCO aprova as fases da Reserva da Biosfera da Mata Atlântica. \\
\hline
\end{tabular}


(conclusão)

\begin{tabular}{|l|l|}
\hline Ano & Ações de defesa da biodiversidade \\
\hline 1993 & Criação, pelo CONAMA, da Câmara Técnica Temporária da Mata Atlântica. \\
\hline 1997 & $\begin{array}{l}\text { Inquérito Civil instaurado pela Procuradoria da República em Ilhéus para apurar irregularidades } \\
\text { de exploração madeireira no sul da Bahia. } \\
\text { Primeiro encontro da Rede de Advogados Ambientalistas da Mata Atlântica, em S. Paulo. }\end{array}$ \\
\hline
\end{tabular}

Fonte: Adaptado de Lima e Capobianco (1997).

Em 2000 é estabelecida a Lei $\mathrm{n}^{\circ} 9.985$ de 18 de julho - Sistema Nacional de Unidades de Conservação da Natureza (SNUC) (BRASIL, 2000). Essa lei normatiza os procedimentos e critérios de criação e gestão das Unidades de Conservação. Assim, as UCs classificam-se em dois grupos: I - Unidades de Proteção Integral; II - Unidades de Uso Sustentável.

As UCs do primeiro grupo têm por objetivo preservar a natureza, admitindo apenas o uso indireto dos seus recursos naturais, com exceção dos casos previstos na Lei. As do segundo grupo destinam-se a compatibilizar a conservação da natureza com o uso sustentável de parcela dos seus recursos naturais (BRASIL, 2000). Nesse grupo, juntam-se às demais as Áreas de Proteção Ambiental (APAs), definidas como:

[...] área em geral extensa, com um certo grau de ocupação humana, dotada de atributos abióticos, bióticos, estéticos ou culturais especialmente importantes para a qualidade de vida e o bem-estar das populações humanas, e tem como objetivos básicos proteger a diversidade biológica, disciplinar o processo de ocupação e assegurar a sustentabilidade do uso dos recursos naturais (BRASIL, 2000, p.11).

A gestão das APAs brasileiras apresenta-se como um enorme desafio aos poderes federais, estaduais, municipais e da sociedade civil, devido a sua configuração englobando propriedades privadas e estruturas sócioculturais e econômicas diversificadas e com aspirações de desenvolvimento individual e/ou coletivo e conflitos associados, levando à necessidade de consolidar a conservação dos atributos ambientais, a cultura e tradições locais - identidade local-, respeitando o dinamismo com que esses aspectos se configuram (VALLE, 2010; HOEFFEL;FADINI; SEIXAS, 2010).

\subsection{As áreas de conservação da biodiversidade em Moçambique}

Moçambique, à semelhança dos outros países africanos, asiáticos e latino-americanos, esteve sob dominação colonial estrangeira europeia. Associado à especulação e expropriação de territórios indígenas, o regime colonial português em Moçambique desencadeou ações de 
conservação da biodiversidade, a partir dos anos 30 do séc. XX, com a criação do Parque Nacional da Gorongosa, na Província central de Sofala, em 1935. Dezenove anos mais tarde criou-se a Reserva Parcial de Caça do Niassa, cuja legislação esteve a serviço do domínio imperialista português. A maioria das áreas de conservação no país foi estabelecida no período Pós-Independência Nacional (BIOFUND - Fundação para a Conservação da Biodiversidade), proclamada a 25 de junho de 1975, pelo Saudoso Presidente da República de Moçambique, Samora Moisés Machel. A partir de 1981, Moçambique é signatário de vários protocolos e convenções internacionais sobre a conservação da biodiversidade: Convenção Africana sobre a Conservação da Natureza e dos Recursos Naturais (Resolução no 18/1981); Convenção da Diversidade Biológica (1995); Primeira Estratégia Nacional e Plano de Ação para a Conservação da Biodiversidade para 2003 a 2010; Declaração de Londres sobre o Tráfico Ilegal de Espécies e Protocolo de Nagoya sobre Acesso a Recursos Genéticos e Partilha Justa e Equitativa dos Benefícios Derivados de sua Utilização à Convenção sobre Diversidade Biológica (2014) (COUTO, 2014; MITADER, 2015).

Com o fim das hostilidades político-militares que duraram 16 anos em Moçambique, desde 1990, os procedimentos e critérios de estabelecimento e gestão de áreas de conservação terrestres e marítimas baseavam-se nas leis do ambiente (Lei n ${ }^{\circ}$ 20/97 de 1 de outubro); de terras (Lei no 19/97 de 1 de outubro); de florestas e fauna bravia (Lei no 10/99 de 7 de julho); de pescas (Lei ${ }^{\circ}$ 3/90 de 26 de setembro). Com base nesses instrumentos foram desencadeadas ações de restauração das áreas de conservação outrora ameaçadas pelo conflito armado, fato que levou a que em 2009 fosse aprovada a primeira Política de Conservação e Estratégia de sua Implementação (Resolução no 63/2009 de 2 de novembro) e, mais tarde, a própria lei de Proteção e Conservação da Biodiversidade (Lei no 16/2014 de 20 de junho), que recentemente veio a ser alterada e republicada pela Lei no 5/2017 de 11 de maio. Ainda em 2017 foi aprovado o Regulamento da Lei de Conservação (Decreto no 89/2017 de 29 de dezembro).

Após a breve contextualização sobre as Unidades de Conservação da Biodiversidade do Brasil e de Moçambique, serão apresentados a seguir os aspectos metodológicos que nortearam esta pesquisa nas três áreas estudadas (a Mata Santa Genebra, Serra do Japi e Reserva Nacional do Niassa). 


\section{Metodologia}

\subsection{As áreas do estudo}

Nesta parte faz-se a caracterização das Unidades de Conservação da Biodiversidade objetos de estudo nomeadamente: a Serra do Japi e a Mata Santa Genebra (do Brasil) e a Reserva Nacional do Niassa (de Moçambique).

\subsubsection{A Serra do Japi}

Essa Serra, com aproximadamente $350 \mathrm{~km}^{2}$ (BALLERINI;GALHARDI, 2014) de superfície, está contida na Reserva de Biosfera da Mata Atlântica brasileira e foi considerada pela ONU como patrimônio natural da humanidade. A mesma faz parte da zona de amortecimento do cinturão verde da cidade de São Paulo e situa-se entre os municípios de Jundiaí, Cabreúva, Pirapora do Bom Jesus e Cajamar (Figuras 1 e 2). As áreas tombadas situamse junto do principal corredor regional do estado, formando ao longo da Rodovia Anhanguera e, posteriormente, acentuado pela Rodovia dos Bandeirantes. As referidas vias dão acesso ao município de Jundiaí que, além de deter a maior área (47.67\%) da superfície total, do ponto de vista regional constitui a melhor referência (VIEIRA et al, 1989; BALLERINI; GALHARDI, 2014) e é onde se situa a Base Ecológica da Serra.

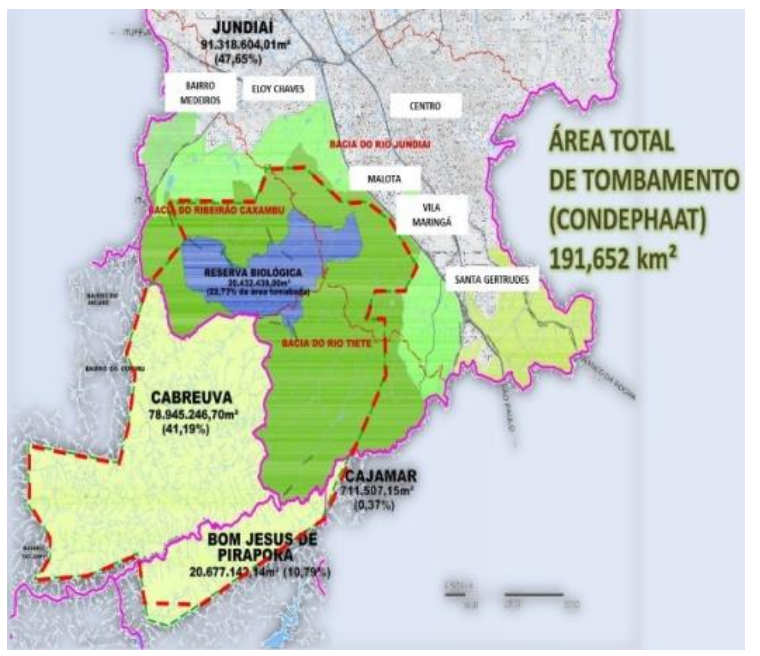

Figura 1 - Localização geográfica da Serra do Japi Fonte: https://serradojapi.jundiai.sp.gov.br/

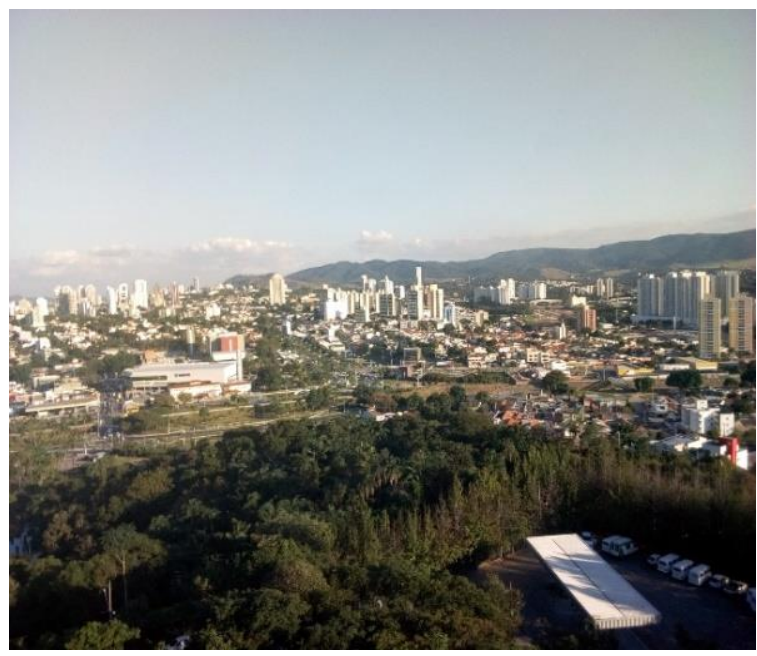

Figura 2 - Vista parcial da Serra do Japi Fonte: Autores (2018)

\subsubsection{A Mata Santa Genebra (MSG)}

A Área de Relevante Interesse Ecológico (ARIE) da MSG, com uma superfície de 251.7 hectares (VIKIAVES, 2018; CAMARGO, 2008; SERRÃO, 2002), localiza-se à norte do município de Campinas, em São Paulo, Brasil, ao largo da Rua Mata Atlântica 447, no Distrito de Barão Geraldo, bairro Bosque de Barão, entre as coordenadas geográficas $22^{\circ} 44^{\prime} 45^{\prime}$ 'S e 
4706’33'’W (GUIRÃO; TEIXEIRA FILHO, 2011; MINISTÉRIO DO MEIO AMBIENTE, 2010) (Figuras 3 e 4).

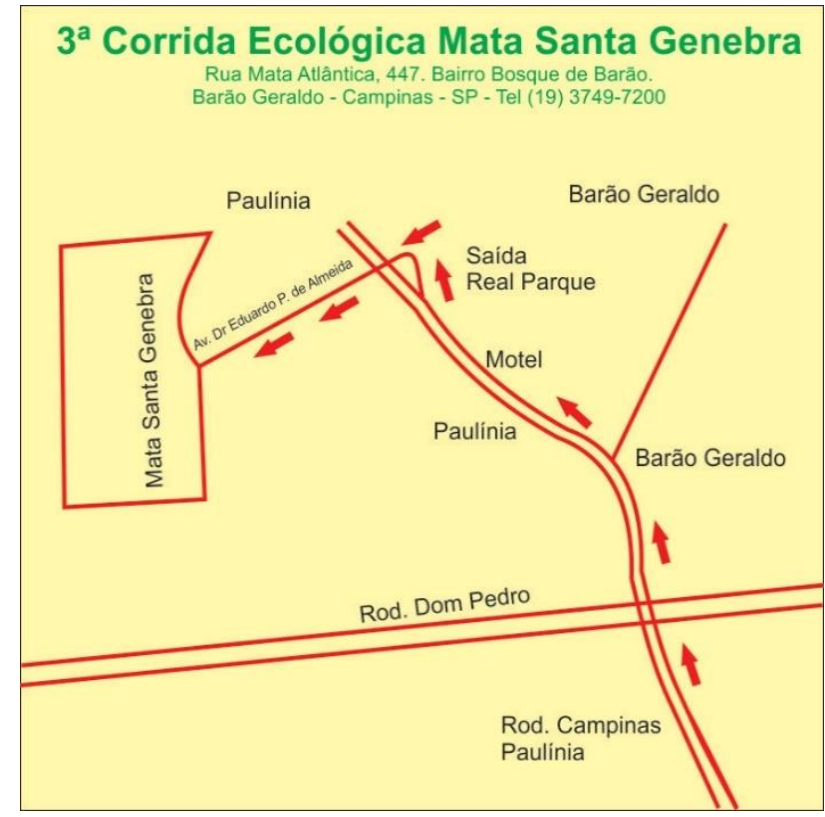

Figura 3 - Localização geográfica da MSG

Fonte: http://www.corpuseventos.com.br/corrida/images/mapa_santa_genebra.jpg

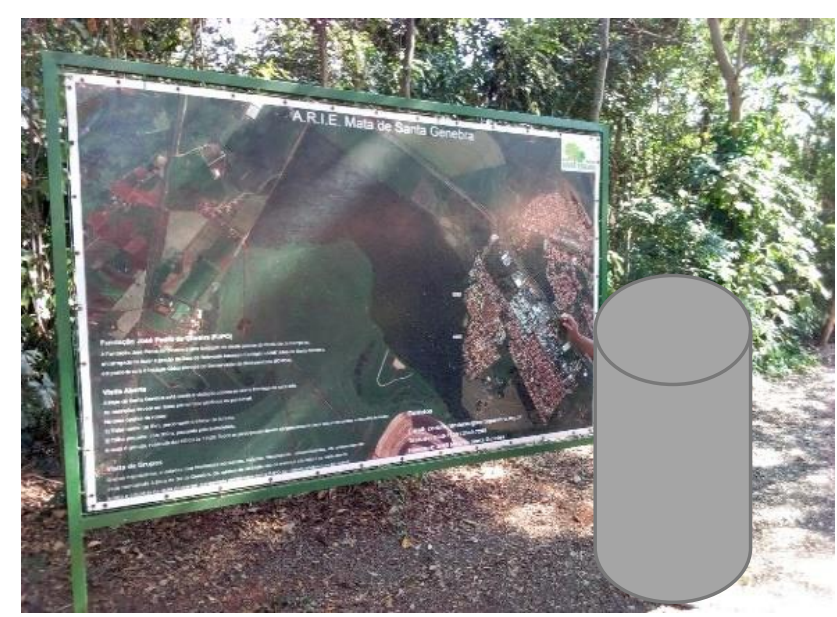

Figura 4 - Placa indicativa da MSG

Fonte: Autores (2018)

\subsubsection{A Reserva Nacional do Niassa}

A Reserva Nacional do Niassa, com $42.400 \mathrm{~km}^{2}$ (CRAIG, 2009) (Figura 5), levou o nome da Província nortenha de Moçambique (Niassa), na qual se localiza geograficamente. Na sua maioria localiza-se nos distritos de Mecula (100\% do território) e Mavago (98\% do 
território) e estende-se por mais alguns distritos dessa Província e de Cabo-Delgado, cujos territórios constituem a sua buffer-zone ${ }^{8}$.

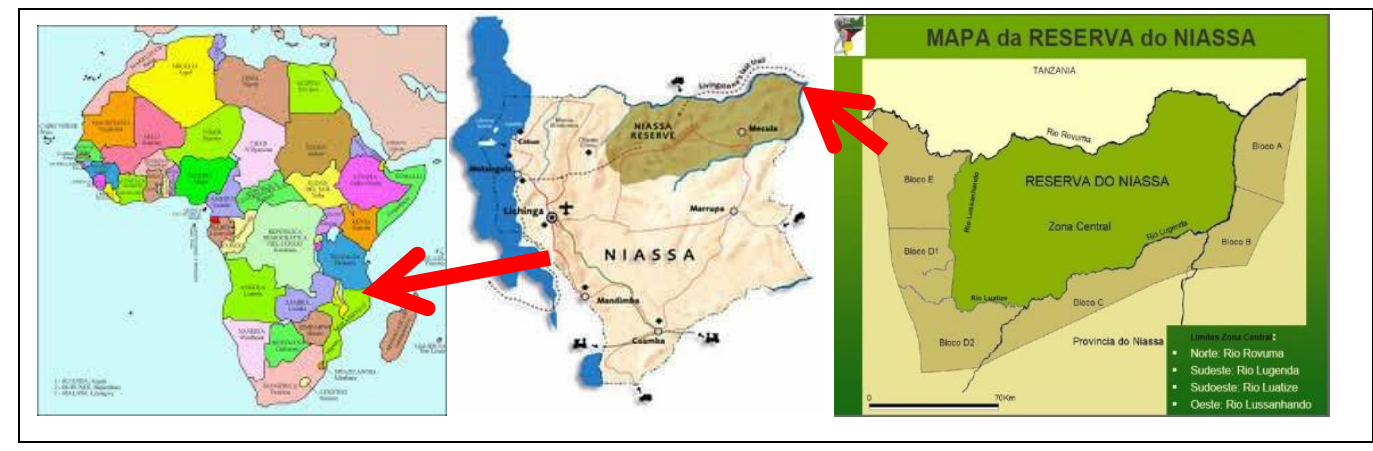

Figura. 5: Localização geográfica da RNN no contexto Africano

Fonte: http://cuamba.blogspot.com/2009/06/reserva-natural-do-niassa.html

Metodologicamente, a pesquisa consistiu basicamente em levantamento bibliográfico e documental. Adicionalmente foram realizadas visitas de estudo que privilegiaram o diálogo com os gestores e residentes em áreas contíguas e/ou do interior dessas áreas de conservação. Nas duas áreas de conservação brasileiras o trabalho decorreu em três momentos: i) agendamento da visita através do site da Instituição; ii) participação no $2^{\circ}$ Seminário de Pesquisas e Educação Ambiental da Serra do Japi no dia 19 de junho de 2018 e; diálogo com os responsáveis e participantes do seminário. A visita à Mata Santa Genebra foi igualmente na última quinzena do mês de junho de 2018, na qual se privilegiou o diálogo com os colaboradores institucionais e alguns moradores. A Reserva Nacional do Niassa é a área-objeto de pesquisa da tese de doutorado em andamento desde o ano de 2016, por isso, as visitas nessa área têm sido sistemáticas. Nos três lugares visitados, a observação foi a técnica utilizada para a coleta de dados sobre essas Unidades de Conservação. Como afirmam Marconi e Lakatos (2007), a observação:

[...] é uma técnica de coleta de dados para conseguir informações e utiliza os sentidos na obtenção de determinados aspectos da realidade. Não consiste apenas em ver e ouvir, mas também em examinar fatos ou fenômenos que se deseja estudar.

A observação utilizada foi sistemática e intencional (MARCONI; LAKATOS, 2007, p. 90), com recurso a meios de captação fotográfica para um melhor registo e compreensão da evolução das paisagens e seus marcos históricos. Os resultados desta pesquisa são apresentados nos parágrafos a seguir.

\footnotetext{
${ }^{8}$ Zona de amortecimento ou zona-tampão.
} 


\section{Análise e discussão dos resultados}

O tombamento da Serra do Japi foi estabelecido pelo Decreto Estadual número 13.426 de 16 de março de 1979 (VIEIRA et al. 1989; GERONDI, 2005), todavia Ballerini (2014) e Yoshida e Gonçalves (2004) referem que o tombamento foi em março de 1983 e 1984, respectivamente. Essa região é constituída por importantes acidentes topográficos e geológicos das serras do Japi, Guaxinduva e Jaguacoara nos municípios indicados na tabela abaixo. A riqueza hídrica da Serra mereceu a denominação de "Castelo de Águas", principalmente pelo Professor Aziz Nacib Ab’Saber (VIEIRA et al., 1989; PORTAL PREFEITURA DO MUNICÍPIO DE JUNDIAÍ, 2018). Segundo Vieira et al. (1989) os seus limites dispõem-se em forma de um polígono irregular de 31 vértices, com um eixo maior de $21.800 \mathrm{~m}$ e um eixo menor de $12.700 \mathrm{~m}$, correspondendo a uma área de aproximadamente 19.170 hectares, distribuídos como consta na Tabela 1:

Tabela 1: Territórios ocupados pela Serra do Japi

\begin{tabular}{|l|r|r|}
\hline \multicolumn{1}{|c|}{ Município } & \multicolumn{1}{c|}{ Área (ha) } & Percentual (\%) \\
\hline Jundiaí & 9.140 & 47.67 \\
\hline Cabreúva & 7.890 & 41.16 \\
\hline Pirapora do Bom Jesus & 2.010 & 10.49 \\
\hline Cajamar & 130 & 00.68 \\
\hline Total & 19.170 & 100 \\
\hline
\end{tabular}

Fonte: Vieira et al. (1989)

Está estabelecida uma Base Ecológica da Serra, gerida pela Fundação Serra do Japi, que promove ações de conservação in situ e ex situ. A UNICAMP, através do Instituto de Biologia, desenvolve diversos estudos sobre a preservação da biodiversidade da Serra, com especial atenção para as borboletas, cujos resultados foram igualmente divulgados e debatidos no seminário referido anteriormente.

Em relação a Mata Santa Genebra, na qual de acordo com o Portal da Mata Santa Genebra (2018) parte da vegetação nativa é remanescente de Mata Atlântica (BARBOSA, FORMAGIO \& BARBOSA, 2010; CAMARGO, 2008), sua criação esteve relacionada à produção de commodities de café e designava-se Fazenda Santa Genebra - propriedade do Senhor Barão Geraldo de Resende, cuja superfície abrangia o Distrito de Barão Geraldo e algumas áreas da Cidade de Campinas (atualmente do outro lado da Rodovia D. Pedro I). Mais tarde, essa área passou a pertencer ao Senhor José Pedro de Oliveira, cuja paixão pela preservação da mata relacionou-se a motivos de sua saúde, face à melhor qualidade dos serviços 
ambientais providos por aquele bioma, fato que lhe proporcionou a manutenção do nome "Mata Santa Genebra” (PORTAL DA MATA SANTA GENEBRA, 2018; MINISTÉRIO DO MEIO AMBIENTE, 2010).

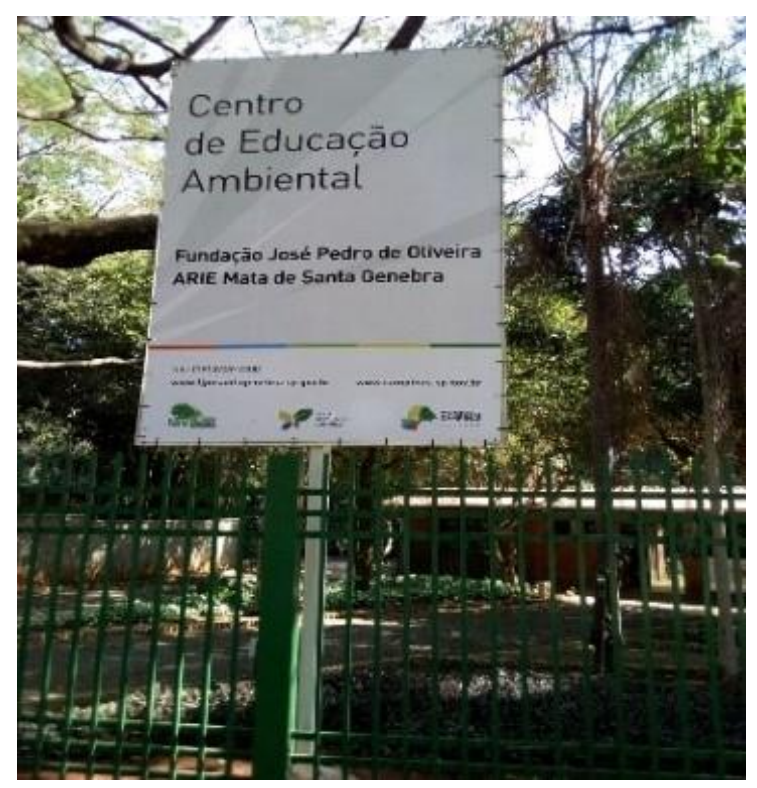

Figura 6: Mata Santa Genebra Fonte: Francisco Nhachungue (2018)

O Ministério do Meio Ambiente (2010) indica que após a sua doação ao município de Campinas pela família Oliveira, a Mata Santa Genebra foi registada pela Lei Municipal n 5118 , de 14 de julho de 1981, e simultâneamente como Fundação José Pedro de Oliveira ${ }^{9}$ (FJPO), passando a fins científicos e culturais. A Resolução n ${ }^{0}$ 3/83 de 3 de fevereiro conferiu à área tombada, pela primeira vez, o reconhecimento de Patrimônio Natural pelo Conselho de Defesa do Patrimônio Histórico, Artístico, Arqueológico e Turístico do Estado de São Paulo (CONDEPHAAT) (MINISTÉRIO DO MEIO AMBIENTE, 2010). A segunda foi através da Resolução no 11 de 29 de setembro de 1992, pelo Conselho de Defesa do Patrimônio Artístico e Cultural de Campinas (CONDEPACC). Tratando-se de uma Unidade de Conservação de âmbito Federal, a ARIE ${ }^{10}$ da Mata Santa Genebra subordina-se ao Instituto Chico Mendes para Conservação da Biodiversidade (ICMBio) ${ }^{11}$.

\footnotetext{
9 À entrada da Mata, denota-se a Placa com a designação da Fundação José Pedro de Oliveira, como ilustra a figura. 6.

10 ARIE (Área de Relevante Interesse Ecológico). A Mata passou a essa categoria por meio do Decreto Federal $\mathrm{n}^{\mathrm{o}}$ 91.885 de 5 de novembro de 1985 .

${ }^{11} \mathrm{O}$ ICMBio é um órgão vinculado ao Ministério do Meio Ambiente e vocaciona-se à administração das Unidades de Conservação.
} 
A Reserva Nacional do Niassa ${ }^{12}$ (RNN), outrora Reserva Parcial de Caça, foi fundada através da Portaria no 10.578 de 9 de outubro de 1954 (MOÇAMBIQUE, 1954; SRN, 2006). A área é eminentemente rural, que preserva a fauna e vegetação característica de miombo (SRN, 2006). Na sua central e no entorno a RNN é habitada por população que se dedica às atividades do setor primário (MAE, 2005) baseadas na agricultura itinerante sob queimadas, caça de algumas espécies faunísticas e coleta de diversos (sub) produtos da floresta tropical. A figura 7 ilustra a placa situada à entrada da Reserva, precisamente na área sob gestão da Unidade L7.

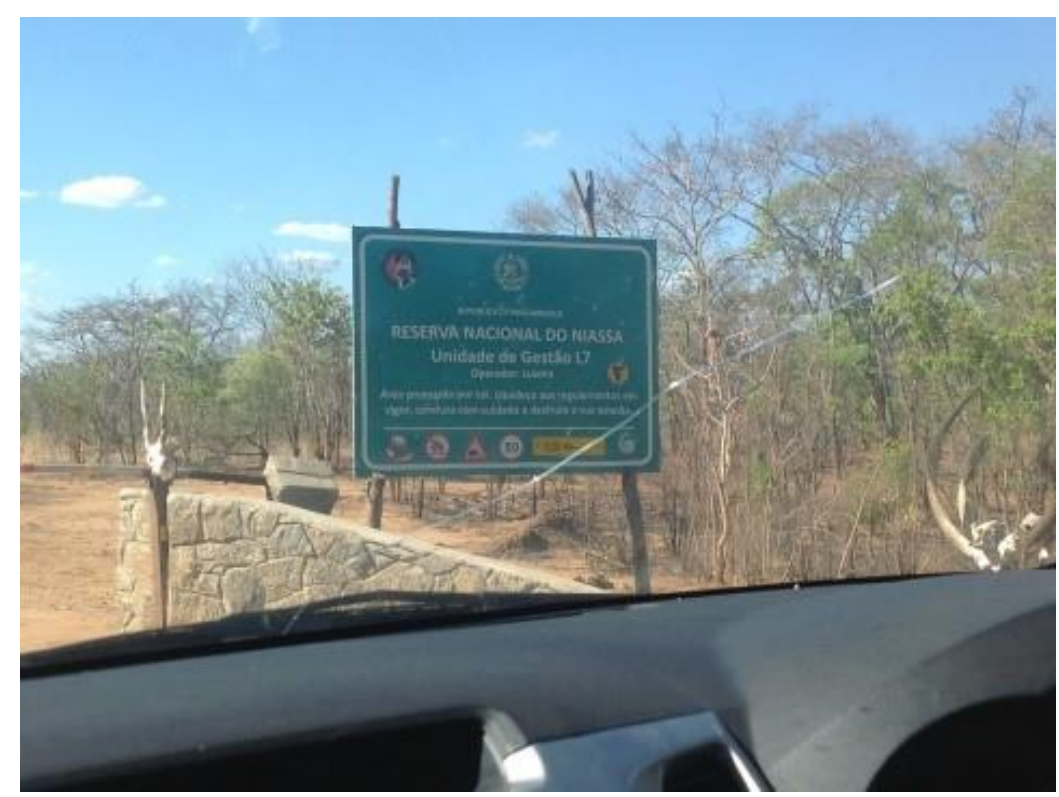

Figura 7: Reserva Nacional do Niassa (RNN)

Fonte: Francisco Nhachungue (2018)

A sua gestão passou por três momentos importantes: além do período colonial, o primeiro momento foi caracterizado pelo modelo de gestão eminentemente pública, a contar desde a Independência Nacional em 1975 e durante o conflito armado ora terminado em 1992, o Estado detinha $100 \%$ de poderes de gestão através do Ministério da Agricultura. Com o fim do conflito armado, desencadearam-se ações de restauração da Reserva em 1995, coordenadas pelo Estado, através dos Serviços Provinciais de Floresta e Fauna Bravia do Niassa e o Grupo Madal junto da Sociedade de Gestão da Reserva Nacional do Niassa (SRN, 2006). Era a experiência pioneira de cogestão em parceria público-privada. O terceiro momento estende-se desde 2002 até 2012, época em que prevaleceu a parceria público-privada constituída pela Sociedade de Gestão de Reserva Nacional do Niassa com $49 \%$ de ações e o Estado detentor de $51 \%$ de ações sobre a gestão da Reserva. De 2014 à atualidade, a Reserva é gerida sob o modelo

\footnotetext{
${ }^{12}$ Criada pelo Decreto $\mathrm{n}^{\circ}$ 81/99 de 16 de novembro, atribuindo-lhe novos limites diferentes dos apresentados na sua fundação através da Portaria no 10.578 de 9 de outubro de 1954.
} 
de parceria público-privada e comunidades locais. O modelo atual levou à adequação do Plano de Manejo (iniciado em finais de 2018 e ainda não publicado) à nova legislação moçambicana de conservação ${ }^{13}$ e também às aspirações das comunidades locais. As propostas de novo zoneamento da RNN levaram à sua recategorização, passando a pertencer à categoria de manejo das áreas de conservação de uso sustentável, ou categoria VI da $\mathrm{IUCN}^{14}$, e, no contexto do SNUC brasileiro, equipara-se com a categoria VI - Reserva de Desenvolvimento Sustentável, do grupo II - Unidades de Uso Sustentável. Assim está previsto o seguinte zoneamento: i) área de proteção total; ii) área de desenvolvimento turístico; iii) área de uso controlado e; iv) área de desenvolvimento comunitário (REPÚBLICA DE MOÇAMBIQUE, 2017).

A Mata Santa Genebra tem modelo de gestão estabelecido no Termo de Reciprocidade $\mathrm{n}^{\mathrm{o}}$ 01/2010 de 23 de fevereiro, estabelecendo uma gestão compartilhada pelo ICMBio+PMC ${ }^{15}+$ FJPO (PORTAL DA MATA SANTA GENEBRA, 2018; CAMARGO, 2008). Incluída no Grupo de Unidades de Uso Sustentável a preservação da MSG tem por objetivo compatibilizar a conservação da natureza com o uso sustentável de parcela dos seus recursos naturais (MINISTÉRIO DO MEIO AMBIENTE, 2010). A FJPO ${ }^{16}$ é um órgão de administração indireta da Prefeitura Municipal de Campinas e gestor da ARIE da MSG com a finalidade de administrar, conservar e preservar a mata, possibilitando a realização de estudos, pesquisas, educação ambiental e outras atividades de cariz científico-cultural (MINISTÉRIO DO MEIO AMBIENTE, 2010). O entorno da MSG é subdividido por fragmentos de floresta de brejo, com inúmeras nascentes. De acordo com o Ministério do Meio Ambiente (2010) esses fragmentos são denominados por Bem Natural B, Bem Natural C, Bem Natural C e Bem Natural D, dos quais apenas C e D são tombados pelo CONDEPACC. A MSG subdivide-se por 2 (duas) zonas principais: i) zonas internas (de proteção, visitação, recuperação e zona da administração); ii) zona de amortecimento. A zona de proteção é equipada de sistemas de câmeras de vigilância e alarme de segurança interna, como reforço à fiscalização.

A Reserva Biológica da Serra do Japi (RBSJ), de acordo com Prefeitura de Jundiaí (2008), tem 2.071 hectares, foi criada pela Lei Municipal no 3.672 de 10 de janeiro de 1991, regulamentada pelo Decreto Municipal no 13.196 de 30 de dezembro de 1992 e representa um importante fragmento florestal rico em recursos hídricos e biodiversidade florística e faunística

\footnotetext{
${ }^{13}$ Lei $\mathrm{n}^{\mathrm{o}}$ 16/2014 de 20 de junho alterada e republicada pela Lei $\mathrm{n}^{\mathrm{o}}$ 5/2017 de 11 de maio; e o Decreto $\mathrm{n}^{\mathrm{o}}$ 89/2017 de 29 de dezembro.

14 Área protegida de uso sustentável dos recursos.

15 PMC - Plano de Manejo Comunitário.

${ }^{16}$ Fundação José Pedro de Oliveira.
} 
da Serra do Japi, localizada em uma região ecotonal de dois tipos de florestas: a Mata Atlântica da Serra do Mar e a Mata Atlântica do interior paulista (PREFEITURA DE JUNDIAÍ, 2008). A RBSJ enquadra-se na categoria de Unidades de Conservação de Proteção Integral, do SNUC brasileiro, na qual apenas se permitem atividades de pesquisa e educação dentro dos seus limites. Com a particularidade de não se situar em faixa de fronteira internacional, a Reserva está em zona de amortecimento da Reserva da Biosfera do Cinturão Verde da Cidade de São Paulo (instituído pelas Nações Unidas em 1994), integrante da Rede Mundial de Reservas da Biosfera do Programa "Man and Biosphere" (PREFEITURA DE JUNDIAÍ, 2008). A RBSJ caracteriza-se pelas seguintes zonas: i) zona intangível (proteção total, permitindo-se a fiscalização intensiva e pesquisa restrita de menor impacto possível); ii) zona primitiva (onde tenha ocorrido menor impacto possível e permite-se a fiscalização e pesquisa; iii) zona de recuperação (as consideravelmente alteradas ou degradadas pelo homem e nelas permite-se a fiscalização, pesquisa, monitoramento, educação ambiental: demonstração de processos de regeneração/recuperação); iv) zona de Uso Educativo e Especial; v) zona de amortecimento. Esse zoneamento baseou-se nos seguintes critérios: grau de conservação da vegetação, variabilidade ambiental, representatividade, diversidade, áreas de transição, suscetibilidade ambiental, potencial de visitação, presença de infraestruturas e usos conflitantes (PREFEITURA DE JUNDIAÍ, 2008).

Após as discussões que nos levam ao melhor conhecimento dessas três áreas de conservação da biodiversidade, são apresentadas, a seguir, as considerações finais.

\section{Considerações finais}

Os remanescentes da Mata Atlântica brasileira, com destaque para a Reserva Biológica da Serra do Japi, a Mata Santa Genebra e a Reserva Nacional do Niassa apresentam alguns pontos equiparáveis e outros divergentes. Essas três áreas de conservação, apesar de se localizarem em contextos físicos e geopolíticos distintos, têm algo em comum: i) passaram pela gestão colonial com interesses imperialistas europeus; ii) registaram processos de degradação dos recursos ambientais; iii) os modelos de gestão dessas áreas de conservação são por parcerias público-privadas (PPP). Nos aspectos divergentes destacam-se: i) características físicogeográficas; ii) enquanto as Unidades de Conservação brasileiras enfrentam processos de crescimento urbano, industrialização, especulação mobiliária, privatização de terras para fins agropecuários e condomínios, a Reserva Nacional do Niassa, sendo uma área eminentemente 
rural, é acometida por atividades predatórias aos recursos ambientais e extrativismo dos recursos para fins de subsistência familiar.

As práticas agrícolas itinerantes com recurso às queimadas descontroladas, caça ilegal, pesca de arrasto para subsistência são algumas das atividades que desafiam as ações de gestão e administração da Reserva Nacional do Niassa (RNN); ii) as duas unidades brasileiras são APAs, enquadradas nas categorias VI (Áreas Protegidas de Uso Sustentável dos Recursos) e categoria I, grupo II (Unidades de Uso Sustentável) da IUCN e SNUC, respectivamente. O seu modelo de gestão é público + privado + comunidades locais. O setor público é representado pelo Instituto Chico Mendes para a Conservação da Biodiversidade (ICMBio), o setor privado representado pelas Fundações da Serra do Japi e a de José Pedro de Oliveira, da Mata Santa Genebra, respectivamente.

E as comunidades locais e ONGs em ambas as Unidades de Conservação estão representadas em Conselhos Consultivos, Comitês de Gestão com subdivisões específicas. iii) Os mecanismos de financiamento que possibilitam a melhoria dos processos de fiscalização e segurança da integridade dos recursos ambientais são diferenciados entre essas três áreas estudadas.

A RNN, apesar da concepção do plano de manejo que altera a sua categoria e designação, passando a Reserva Especial, carece de medidas de melhoramento de proteção e monitoramento das atividades rotineiras da população. Independentemente dos pontos de concórdia e de discórdia é importante o estabelecimento de mecanismos de trocas de experiências de gestão dessas áreas, pois todas têm uma característica em comum, o fato de serem habitadas por populações no seu interior e no seu entorno.

\section{Referências}

BALLERINI, Adriana Perroni; GALHARDI, Antonio César. A importância dos Serviços Ecossistêmicos e da Gestão Sustentável de um Patrimônio Natural. In: WORKSHOP DE PÓS-GRADUAÇÃO E PESQUISA DO CENTRO PAULA SOUZA, 9., São Paulo. Anais [...] Centro Paula Souza, São Paulo, 2014. p. 59-71.

BARBOSA, Sônia Regina da Cal Seixas; FORMAGIO, Cessimar de Campos; BARBOSA, Rebeca Veiga. Áreas protegidas, uso e ocupação do solo, qualidade de vida e turismo no litoral norte paulista: algumas reflexões sobre o município de Ubatuba. Caderno Virtual de Turismo, Campinas, v. 10, n. 2, p. 121-137, 2010.

BRASIL. Lei no 9.985, de 18 de julho de 2000. Instituiu o Sistema Nacional de Unidades de Conservação da Natureza. Brasília, 2001. 
BIOFUND. Fundação para a Conservação Biodiversidade. Disponível em: http://www.biofund.org.mz/base-de-dados/plataforma-sobre-as-ac/\#area-niassa. Acesso em: 20 dez. 2019.

CAMARGO, Lívia Junqueira de; LUCA, Andréa Quirino de; SILVA, Jodir Pereira de. Representações sociais acerca do meio ambiente de moradores do entorno de uma Unidade de Conservação em Campinas-SP. In: ENCONTRO NACIONAL DA ANPPAS, 4.J, Brasília. Anais [...] ANPPAS, 2008. p. 1-17.

CHARDONNET, Bertrand. Africa is changing: should its protected areas evolve? Recofiguring the protected areas in Africa, 2019.

CRAIG, G.C. Aerial Survey of Wildlife in the Niassa Reserve and Adjacent Areas. Mozambique, 2009.

COUTO, Madyo. Abordagem estratégica para o combate ao tráfico ilegal de fauna e caça furtiva de elefantes e rinocerontes: Relatório produzido para WWF. Moçambique, 2014.

GERONDI, Gisele. Ecoturismo e sistemas de gestão ambiental: medidas corretivas estão sendo tomadas nos hotéis ecológicos da Serra do Japi / SP. Caderno Virtual de Turismo. Rio de Janeiro, v. 5, n. 2, pp. 63-71, 2005.

Googlearth. https://www.google.com/earth/. Acessao em: 10 jul. 2018.

GUIRÃO, Ângela Cruz; TEIXEIRA FILHO, José. Preservação de um fragmento florestal urbano - estudo de caso: A ARIE Mata de Santa Genebra, Campinas-SP. GEOUSP - Espaço e Tempo, São Paulo, n. 29, p.147-158, 2011.

HOEFFEL, João Luiz de Moraes; FADINI, Almerinda Antonia Barbosa e SEIXAS, Sônia Regina da Cal (Orgs.). Sustentabilidade, Qualidade de Vida e Identidade Local: Olhares sobre as APAs Cantareira (SP) e Fernão Dias (MG). São Carlos: RiMA, 2010.

LIMA, André R.; CAPOBIANCO, João Paulo R. (orgs.). Mata Atlântica: Avanços legais e institucionais para sua conservação. Documentos do ISA. São Paulo, v.4, 1997.

MAE. Perfil do Distrito de Mecula - Província de Niassa. Maputo, 2005.

MARCONI, Marina de Andrade; LAKATOS, Eva Maria. Técnicas de Pesquisa. 6.ed, São Paulo, 2007.

MINISTÉRIO DO MEIO AMBIENTE. Plano de Manejo: ARIE Mata de Santa Genebra. Campinas, 2010.

MITADER. Estratégia e Plano de Acção para a Conservação da Diversidade Biológica em Moçambique (2015-2035). Maputo, 2015.

MOÇAMBIQUE. [Boletim Oficial de Moçambique (1954)]. I Série No 41, 9 de outubro de 1954. 
PORTAL PREFEITURA DO MUNICÍPIO DE JUNDIAÍ. https://jundiai.sp.gov.br/ . Acesso em: 18 jul. 2018.

PORTAL DA MATA SANTA GENEBRA. http://www.fjposantagenebra.sp.gov.br/. Acesso em: 18 jul. 2018.

PREFEITURA DE JUNDIAÍ. Plano de Manejo: Reserva Biológica Municipal da Serra do Japi- Jundiaí-SP. 2008.

REPÚBLICA DE MOÇAMBIQUE. Boletim da República: Publicação oficial da República de Moçambique. 14 Suplemento, I Série, no 203. 29 de dezembro de 2017.

SANTOS, Milton. Por uma Geografia Nova. 5.ed. São Paulo: Edusp, 2002.

Espaço e Método. 5.ed. São Paulo: Edusp, 2008.

SENADO FEDERAL. [Constituição (1988)]. Constituição da República Federativa do Brasil. Coordenada por Denise Zaiden Santos. Brasília, 2016.

SERRÃO, Silvia Maria. Para além dos domínios da Mata: Uma discussão sobre o processo de preservação da Reserva da Mata da Santa Genebra, Campinas, SP. Tese (Doutorado em Ciências de Educação) - Faculdade de Educação, Universidade estadual de Campinas, São Paulo, 2002.

SRN. Plano de Maneio da Reserva Nacional do Niassa (2007-2012). s/1. 2006.

VIEIRA, A. A.; SANTOS, C. Del P.; COSTA e SILVA, F.; PORTO SANTOS, S.; PINHEIRO, S.; SCARABELlO FILHO, S.; SILVA FILHO, W. da C.. Projeto Japi. São Paulo, 1989.

WIKIAVES. http://www.wikiaves.com.br/areas:arie_mata_de_santa_genebra:inicio_Acesso em: 20 ago. de 2019.

YOSHIDA, Claudia Eiko; GONÇALVES, Leandra Regina. Identificação de problemas e ameaças da APA Jundiaí-Cabreúva (Serra do Japi) através da análise dos talões de atendimento da Guarda Municipal de Jundiaí/SP. Bioikos. Campinas, v. 18, n. 2, p. 5-10, 2004. 